\title{
Türkiye Trakyası Bağcılık İklim Göstergelerindeki Uzun Süreli Değişimlerin Değerlendirilmesi
}

\author{
${ }^{1}$ Tekirdağ Bağcılık Araștırma Enstitüsü, Yetiștirme Tekniği Bölümü \\ ${ }^{2}$ Tekirdağ Namık Kemal Üniversitesi, Ziraat Fakültesi, Bahçe Bitkileri Bölümü \\ *Sorumlu yazar: serkan.candar@tarimorman.gov.tr
}

Serkan Candar ${ }^{1 *}$ Tezcan Alço $^{1}$ Ahmet Semih Yaşasın ${ }^{1}$ İlknur Korkutal ${ }^{2}$

Elman Bahar ${ }^{2}$

Geliş Tarihi: 08.02.2019

Kabul Tarihi: 23.09.2019

\section{Öz}

Türkiye'nin en önemli bağcılık alanlarından birisi olan Trakya Bölgesi'nde bağcılık iklim göstergelerinin değişimlerinin incelenmesi amacıyla Etkili Sıcaklık Toplamı, Hidrotermik Gösterge, Heliotermik Gösterge, Huglin Göstergesi, Kuraklık Göstergesi, Gece Serinlik Göstergesi ve Kuruluk Göstergesi uzun dönem ve son altı yıl için (2013-2018) hesaplanmıştır. Tekirdağ, Kırklareli, Çanakkale ve Edirne illeri için hesaplanan göstergeler uzun dönemde ısınma eğilimine işaret ederken, son dönemde yağış ve sıcaklık rejimlerinde istikrarsızlıklar görülmektedir. Bu nedenle, çeşit seçimi ve yetiştirme yönetimi gibi stratejiler belirlenirken, iklim verileri uzun yıllar göz önünde bulundurularak değerlendirilmeli ve 5-10 yıllık değişimler dikkate alınmalıdır. Vejetasyon dönemindeki yetiştiricilik yönetiminde ise orta ve kısa vadeli hava tahminleri incelenmelidir.

Anahtar Kelimeler: Vitis vinifera L., bağcılık, teruar, iklim değişikliği

\section{Evaluation of Long Term Changes for Viticultural Climate Indices in Turkey Thrace}

\section{Abstract}

In order to examine the changes of viticulture climate indicators in Thrace Region, which is one of Turkey's most important wine-growing areas, Winkler Index, Hydrothermic Index, Heliothermic Index, Huglin Index, Drought Index, Cool Night Index and Dryness Index were calculated for long term and last six years (2013-2018). Indicators calculated for Tekirdağ, Kırklareli, Çanakkale and Edirne provinces indicate a tendency to warm up in the long term, while instability in rainfall and temperature regimes has been observed latterly. For this reason, while determining strategies such as selection of varieties and cultivation management, climate data should be taken into consideration for long term and changes in 5-10 years also should be taken into consideration. Medium and short term weather forecasts should be examined in the management of vegetation period.

Key words: Vitis vinifera L., viticulture, terroir, climate change

\section{Giriş}

İklim değişikliği, çevreye ve bağcılığa etkileri nedeniyle küresel düzeyde önemli bir sorun haline gelmiştir. Bu değişikliğin olumsuz etkileri, farklı bağcılık bölgelerinde çeşitli şekillerde görülmektedir. Modellemeler, karasal bölgelerde ve kuzey enlemlerde daha fazla isınmaya işaret etmektedir. Bu süreçte kademeli sıcaklık artışı nedeniyle üreticilerin iklim değişikliğine alışılagelmişin dışında stratejilerle uyum sağlamaları gerekecektir. Tarımsal üretimin ve su kaynaklarının en uygun şekilde yönetimi ancak bir alanın iklim koşullarının tam anlamıyla kavranmasıyla başarılabilir. $\mathrm{Bu}$ nedenle iklim göstergeleri farklı teruarların incelenmesi, çeşit gereksinimlerinin ve bağcıllk bölgelerinin belirlenmesi gibi çalışmalarda araç olarak kullanılmaktadır.

Hava durumu kısa süreli atmosferik koşullardır. İklim ise havanın uzun vadeli ortalaması olup, aşırı hava olaylarından kaynaklanan potansiyel tehlikeleri içerir (Sensoy ve Tastekin, 2005). Buna göre uzun süreli ve istikrarlı şartları yansıtan iklimin aksine hava durumu değişkendir (EPA, 2013). Bu nedenle, tarım, doğal kaynaklar, afet yönetimi, kentleşme ve ulaştırma gibi birçok faaliyetin uygun şekilde yönetimi ve değerlendirilmesi için iyi bir iklim bilgisi hayati önem taşır (FAO, 2013; Özelkan ve ark., 2014).

Trakya, güneybatı Bulgaristan (Kuzey Trakya), kuzeybatı Yunanistan (Batı Trakya) ve Türkiye sınırlarında kalan Doğu Trakya bölgelerinden oluşmaktadır. Sınırları kuzeyde Balkan Dağları, güneyde Rodop Dağları ve Ege Denizi ile Doğuda Karadeniz ve Marmara Denizi'dir. Günümüzde 
Trakya topraklarının en büyük kısmı Bulgaristan sınırları içindedir. Türkiye Trakyası olarak ifade edilen Doğu Trakya Bölgesi Kuzeybatı Türkiye'de $26^{\circ}-29^{\circ} 2^{\prime} \mathrm{D}$ ve $40^{\circ}-42^{\circ} 2^{\prime} \mathrm{K}$ koordinatlarındadır. Kuzeyinde Yıldız Dağları ( 1000 m) güneyinde ise Ganos (956 m) ve Koru Dağları (726 m) bulunur. Doğu Trakya, Türkiye topraklarının toplam yüzey alanının yaklaşık \%3'ünü kaplamaktadır (Zdanowski 2014). Trakya Bölgesi, topoğrafik, iklimsel ve biyolojik olarak tekdüzedir. Karadeniz sınırının toprak yapısı şist özellikte olup Anadolu'nun kuzey sıradağlarının düşük irtifada devamlılığını göstermektedir. Karasal özellik gösteren kısım, Ergene Nehri tarafından drene edilen ovalardan oluşmaktadır. Marmara Denizi'nin kuzey sınırı Ganos (Işıklar) Dağı boyunca Gelibolu yarımadasına devam eden bölgede ise Avrupa ile Asya kıtalarının toprak yapısını ayıran kumtaşı karakteri görülmektedir (Immerfall, 2009).

Günümüzde Türkiye Trakyası; Edirne, Kırklareli, Çanakkale, Tekirdağ ve İstanbul'un Avrupa kıtasındaki bölgelerini kapsamaktadır. Trakya bölgesinde iklim, coğrafi konum ve yer şekillerinin fiziki karakteristikleriyle şekillenmektedir. Ege, Marmara ve Karadeniz ile çevrili Trakya'nın kıyı bölgeleri deniz ikliminin, iç kısım ise karasal iklimin etkisi altındadır. Güneyde sahiller boyunca tipik Akdeniz iklimi hakimdir. Bölgenin kuzeyi ve sahilleri daha nemli ve serindir (Papp ve Sabovijevic 2003). Görülen bu iki farklı iklimin farklı yağış rejimleri oluşturması ve iklim değişikliği etkileriyle yıllık yağı̧̧ özelliklerinin giderek farklılaşması (Gönençgil, 2012), olağanüstü hava olaylarının (don, sıcak hava dalgaları, hortum vs.) sıklı̆̆ının artması (Jones, 2006; Donat ve ark., 2013) önümüzdeki süreçte bağcılık uğraşını zorlaştıran iklim etkileri olarak öne çıkmaktadır.

Bu çalışmada Edirne, Kırklareli, Çanakkale ve Tekirdağ illerinin uzun yıllar ve son dönem iklim verileri bağcılık iklim göstergeleriyle birlikte yorumlanarak, bölgenin süregelen iklim değişikliğinden nasıl etkileneceği ve alınması gereken önlemler değerlendirilmiştir.

\section{Materyal ve Yöntem}

\section{İklim Verileri}

Uzun dönem iklim verileri Tekirdăg (1939-2017), Kırklareli (1959-2017), Çanakkale (19282017) ve Edirne (1930-2017) için ve son altı y1l için değerlendirmeleri bu ise 2013-2018 y1llarını kapsayan aralıkta hesaplanmıştır. İklim verileri Meteoroloji Genel Müdürlüğü Meteorolojik Veri Bilgi Satış ve Sunum Sistemi (Mevbis)'nden temin edilmiştir (Çizelge 1).

Çizelge 1. Kısa dönem iklim verilerinin alındığı istasyonların koordinat ve yükseklikleri (2013-2018)

\begin{tabular}{lllll}
\hline İl & İlçe & Enlem & Boylam & Rakım \\
\hline Tekirdă̆ & Süleymanpaşa & 40,95 & 27,49 & 4 \\
Kırklareli & Merkez & 41,73 & 27,21 & 232 \\
Çanakkale & Merkez & 40,14 & 26,39 & 6 \\
Edirne & Merkez & 41.67 & 26,55 & 51 \\
\hline
\end{tabular}

\section{İklim Göstergelerinin Hesaplanması}

\section{Etkili Sıcaklık Toplamı (Winkler Göstergesi) (gün-derece)}

Vejetasyon periyodu içinde $10^{\circ} \mathrm{C}$ üzeri sıcaklıklar toplamı Etkili Sıcaklık Toplamı (EST)' dır. $\mathrm{Bu}$ parametre bir yörenin bağcılığa elverişli olma durumunu belirlemek için kullanıldığ gibi; bir ekolojide üzüm çeşitlerinin olgunlaşabilme potansiyelinin belirlemesi bakımından da yararlı sonuçlar vermektedir (Winkler, 1974; Kunter ve ark., 2017). Ekonomik anlamda bağcılık yapılabilmesi için EST'nin en az 900gün-derece olması gerekir. Bölgeye uyan üzüm çeşidinin belirlenmesinde en önemli iklim kriteridir. Kuzey yarım küre bağcılık kuşağı için $\left(30^{\circ}-50^{\circ}\right.$ kuzey enlemleri) vejetasyon periyodu olan 1 Nisan-31 Ekim arasındaki değerler esas alınarak formül yardımıyla hesaplanır ve iklim sınıfları belirlenir (Çizelge 2).

$\sum_{01.04}^{31.10}(\mathrm{~T} o-10)$

To $=$ Günlük ortalama sıcaklık $\left({ }^{\circ} \mathrm{C}\right)$ 


\begin{tabular}{lc}
\hline Siniflandırma & EST (derece gün) \\
\hline I & $<1371$ \\
II & $1371-1649$ \\
III & $1650-1926$ \\
IV & $1927-2205$ \\
V & $\geq 2205$ \\
\hline
\end{tabular}

\section{Hidrotermik Gösterge (Branas Hidrotermik İndisi) $\left({ }^{\circ} \mathrm{C} . \mathrm{mm}\right)$}

Branas Hidrotermik Göstergesi bağ hastalıklarının (özellikle Mildiyö ve Çürüme) gelişimini izlemede kullanılmaktadır. Vitis vinifera çeşitlerinde $9000^{\circ} \mathrm{C} . \mathrm{mm}$ değerinden sonra hastalık riski fazladır (Branas ve ark., 1946; Carbonneau ve ark., 2007). $2500^{\circ} \mathrm{C} . \mathrm{mm}$ ' nin altında olduğu durumlarda Mildiyö riski bulunmamasına rağmen, $2500-5100^{\circ} \mathrm{C} . \mathrm{mm}$ arasında risk artmaktadır. $5100^{\circ} \mathrm{C} . \mathrm{mm}$ 'den yüksek değerlerde ise Mildiyö ve çürüme açısından bağlarda yüksek risk söz konusu olmaktadır (Malheiro ve ark., 2010)

31 Ekim

IHT $=\Sigma$ T.P formülü esas alınarak hesaplanmaktadır.

1 Nisan

$\mathrm{T}=$ Aylık ortalama sicaklık $\left({ }^{\circ} \mathrm{C}\right)$

$\mathrm{P}=$ Aylık ortalama yağış $(\mathrm{mm})$

Heliotermik Gösterge (Branas Heliotermik İndisi) $\left({ }^{\circ} \mathrm{C} . s a a t\right)$

Heliotermik Gösterge bağcılık bölgelerinin belirlemesi, çeşitlerin adaptasyon özellikleri, fenolojik gelişme ve olgunlaşma süreçlerinin güneş radyasyonu açısından değerlendirilmesinde kullanılır (Branas, 1974). Kuzey yarım kürede Heliotermik Gösterge alt sınırı 2,6'dır. Aşağıdaki formülle hesaplanır.

Branas Heliotermik Göstergesi=X.H.10 ${ }^{-6}$

$\mathrm{X}=$ Y Yllık etkili sıcaklık toplamı $\left({ }^{\circ} \mathrm{C}\right) ; \mathrm{H}=$ Yıllık toplam güneşlenme süresi (saat)

Huglin Heliotermik Göstergesi

Huglin tarafından geliştirilen bu gösterge, 4. ayın başlangıcından 9. ayın sonuna kadar, günlük ortalama ve günlük maksimum sıcaklıklardan; vejetasyon gelişme başlangıcı sıcaklık derecesi olarak kabul edilen $10^{\circ} \mathrm{C}^{\prime}$ nin çıkarılmasıyla elde edilen ortalama değerlerin toplanarak gün uzunluğu katsayısı ile çarpılması ve bunların toplanmasıyla bulunan değerdir (Huglin 1978). Huglin indeksi (Hİ) özellikle şaraplık üzüm çeşitlerinde kalite ile sıcaklık arasındaki ilişkiyi gösterir. Kültür asmanın yetiştiği yerlerde Huglin (1978) ile Tonietto ve Carbonneau (2004)'e göre Hİ=1500'den, Laget ve ark., (2008)'e göre 1600'den aşağı olmamalıdır. İklim sınıfları Çizelge 3'de verilen gösterge şöyle formüle edilmektedir.

$\sum_{01.04}^{30.09} \frac{[(T-10)+(T x-10)]}{2} d$

$\mathrm{T}=$ Günlük ortalama sicaklık $\left({ }^{\circ} \mathrm{C}\right)$

$\mathrm{T} X=$ Günlük en yüksek sıcaklık $\left({ }^{\circ} \mathrm{C}\right)$

$d=$ Gün uzunluğu katsayısı $\left(40^{\circ} 1\right.$ " dan $42^{\circ} 0$ " ya kadar 1,02$)$

Çizelge 3. Huglin Heliotermik Göstergesi iklim sınıfları

\begin{tabular}{lcc}
\hline İklim sınıfi & Kısaltma & Sınıf aralığ \\
\hline Çok soğuk & Hİ -3 & $\mathrm{H} \leq 1500$ \\
Soğuk & $\mathrm{HI}-2$ & $1500<\mathrm{HI} \leq 1800$ \\
Serin & $\mathrm{HI}-1$ & $1800<\mathrm{HI} \leq 2100$ \\
Ilık & $\mathrm{HI}+1$ & $2100<\mathrm{HI} \leq 2400$ \\
Sicak & $\mathrm{H} \dot{\mathrm{I}}+2$ & $2400<\mathrm{HI} \leq 3000$ \\
Çok sicak & $\mathrm{HI}+3$ & $3000<\mathrm{HI}$ \\
\hline
\end{tabular}




\section{Kuraklık Göstergesi}

$\mathrm{Bu}$ gösterge vejetasyon dönemi içindeki toplam yağışın, $10{ }^{\circ} \mathrm{C}$ üzerindeki yıllık toplam aktif sıcaklığa oranı ve bunun 10 ile çarpılmasından bulunan değerdir. K'nın 1'den küçük olan değerler yağışın yetersiz, dolayısıyla kuraklık olduğunu; 1' e yakın veya 1' den büyük değerler yağışın yeterli olduğunu göstermektedir (Bahar ve ark., 2010).

$\mathrm{K}=(\mathrm{P} / \mathrm{T} a) \cdot 10$

$\mathrm{P}=$ Vegetasyon devresindeki toplam yağış $(\mathrm{mm})$

$\mathrm{T} a=$ Y 11 lik toplam aktif sicakl1k $\left({ }^{\circ} \mathrm{C}\right)$

\section{Gece Serinlik Göstergesi (Night cold index) $\left({ }^{\circ} \mathrm{C}\right)$}

Bir bölgedeki gece sıcaklıklarını ifade etmek için kullanılan Gece Serinlik Göstergesi (Tonietto 1999), Eylül ayı içindeki en düşük sıcaklıkların ortalaması olarak hesaplanmaktadır. Özellikle şaraplık çeşitlerde renk ve aromalar için önemli olarak kabul edilmektedir (Tonietto ve Carbonneau 2004). İklim sınıfları Çizelge 4'te gösterilmiştir.

Çizelge 4. Gece Serinlik Göstergesi iklim sinıfları

\begin{tabular}{lcc}
\hline İklim sınıfı & Kisaltma & Sinıf aralı̆̆ 1 \\
\hline Sicak geceler & CI -2 & $18<\mathrm{SGI}$ \\
Ilık geceler & CI -1 & $14<\mathrm{SGI}<18$ \\
Serin geceler & CI +1 & $12<\mathrm{SGI}<14$ \\
Soğuk geceler & CI +2 & SGI $\leq 12$ \\
\hline
\end{tabular}

\section{Kuruluk Göstergesi (Dryness index ) (mm)}

İklim sınıfları Çizelge 5'de paylaşılan Kuruluk göstergesi Riou ve ark., (1994) tarafından geliştirilen toprak potansiyel su dengesi indeksinin bağlarda kullanımı için uyarlanmış halidir. Bir bağcılık bölgesindeki su bileşenlerinin karakterizasyonunu yüzey akışıyla uzaklaşan su ve drenaj hariç, çıplak topraktan meydana gelen evaporasyon ve bağın standart iklim isteklerini hesaba katarak ifade eder. Bir bölgenin kuruluk seviyesini topraktaki potansiyel su mevcudiyeti ile ilişkilendirerek gösterir (Tonietto ve Carbonneau 2004). Üzümün olgunlaşması ve potansiyel şarap kalitesini belirtmesi bakımından önemlidir.

$$
\mathrm{W}=\mathrm{W}_{0}+\mathrm{P}-\mathrm{T}_{\mathrm{v}}-\mathrm{E}_{\mathrm{s}}
$$

Formülü ile ifade edilir. $\mathrm{W}=$ Belirli bir dönemdeki toprak su rezervi. $\mathrm{P}=$ Yağış. $\mathrm{T}_{\mathrm{v}}=$ Bağdaki potansiyel transpirasyon $\left(\mathrm{T}_{\mathrm{v}}=\right.$ ETP. K) ETP, Penman (1948)'e göre hesaplanmış aylık toplam potansiyel evapotranspirasyon ve $\mathrm{k}$ asma tarafindan alınan radyasyon katsayısıdır. $\mathrm{K}$ transpirasyona ve asma taç yapısına göre değişkendir. $E_{\mathrm{s}}$, topraktan doğrudan evaporasyonu $\mathrm{E}_{\mathrm{s}}$, ETP/N.(1-k)JPm $\mathrm{N}=$ hesaplanan aydaki gün sayısı, JPm hesaplanan ayda evaporasyon görülen günlerin sayısıdır. Aylık toplam potansiyel evapotranspirasyon (PET) ise aşağıdaki formül ile hesaplanmıştır.

$$
P E T=\frac{\mathrm{m} R \mathrm{n}+\rho \mathrm{a} c \mathrm{p}(\delta e) g \mathrm{a}}{\lambda \mathrm{v}(m+\gamma)}
$$

$\mathrm{m}=$ Doyma buharı basınç eğrisinin eğimi $\left(\mathrm{Pa} \mathrm{K}^{-1}\right)$

$R, \mathrm{n}=$ Net 1 şınım $\left(\mathrm{W} \mathrm{m}^{-2}\right)$

$\rho$ a $=$ Hava yoğunluğu $\left(\mathrm{kg} \mathrm{m}^{-3}\right)$

$c \mathrm{p}=$ Havanın 1s1 kapasitesi $\left(\mathrm{J} \mathrm{kg}^{-1} \mathrm{~K}^{-1}\right)$

$g$ a $=$ Momentum yüzeyi aerodinamik iletkenliği $\left(\mathrm{ms}^{-1}\right)$

$\delta \mathrm{e}=$ Buhar basıncı açı ğı $(\mathrm{Pa})$

$\lambda \mathrm{v}=$ Gizli buharlaşma isısı $\left(\mathrm{J} \mathrm{kg}^{-1}\right)$

$\gamma=$ Psikrometrik sabiti $\left(\mathrm{Pa} \mathrm{K}^{-1}\right)$ 
Çizelge 5. Kuruluk Göstergesi iklim sınıfları

\begin{tabular}{lcc}
\hline İklim sınıfi & Kisaltma & Sınıf aralı̆̆ 1 \\
\hline Çok kuru & DI +2 & $\leq-100$ \\
Orta kuru & DI +1 & $\leq 50>-100$ \\
Az nemli & DI -1 & $\leq 150>50$ \\
Nemli & DI - 2 & $>150$ \\
\hline
\end{tabular}

\section{Bulgular ve Tartışma}

Tekirdağ'da 1939-2017 yılları arasını kapsayan uzun yıllar iklim verilerine göre; yıllık ortalama sicaklık $14,03{ }^{\circ} \mathrm{C}$ olup, en soğuk ay $4,7^{\circ} \mathrm{C}$ ile Ocak, en sicak aylar $23,8{ }^{\circ} \mathrm{C}$ ile Temmuz ve Ağustos aylarıdır. Yı1lık ortalama yağış miktarı 581,8 mm'dir. En fazla yağışın olduğu dönem EkimMart ayları arası olup vejetasyon periyodunda ortalama yağış miktarı 185,20 mm'dir. Bu değerler merkez ve İstanbul sınırlarından başlayıp Şarköy'e kadar uzanan sahil şeridi için geçerlidir. İç kesimlerde karasallık etkisiyle $1-2{ }^{\circ} \mathrm{C}$, Ganos Dağlarında yükseltinin etkisiyle $3-4{ }^{\circ} \mathrm{C}$ 'ye varan sıcaklık azalmaları görülür. En yüksek olağandışı değerler 2007 yılı Haziran ayında $40,2{ }^{\circ} \mathrm{C}$ ve 2015 yılı Eylül ayında $39,7^{\circ} \mathrm{C}$, en düşük değerler 1942 yılı Ocak ayında $-13,5^{\circ} \mathrm{C}$ olarak gerçekleşmiştir. Hakim rüzgarlar güney ve güney-batı rüzgarlarıdır. En hızlı rüzgar 150,1 km/sa ile 2012 y1lı Kasım ayında görülmüștür. Tekirdağ' da bağıl nem ortalamas $1 \% 76$ ' dır. Ortalama en yüksek nispi nem \%82 ile Ocak ve Aralık aylarında, en düşük nispi nem ise \%23 ile Haziran ayında görülmektedir. Yağış miktarı Aralık ayında en fazla $\left(81,5 \mathrm{~kg} / \mathrm{m}^{2}\right)$, Ağustos ayında $13,3 \mathrm{~kg} / \mathrm{m}^{2}$ miktarı ile en azdır (Şekil 1). Bu durum Tekirdağ'da Akdeniz yağış rejiminin hakim olduğunu göstermektedir. Yağışlı günlerin yıl içindeki dağılımı, en az 2,4 günle Ağustos ayında, en fazla 12,3 gün ile Ocak ayı biçimindedir. Ortalama yağışlı gün sayısı ise 97,3'tür (MGM 2019a).
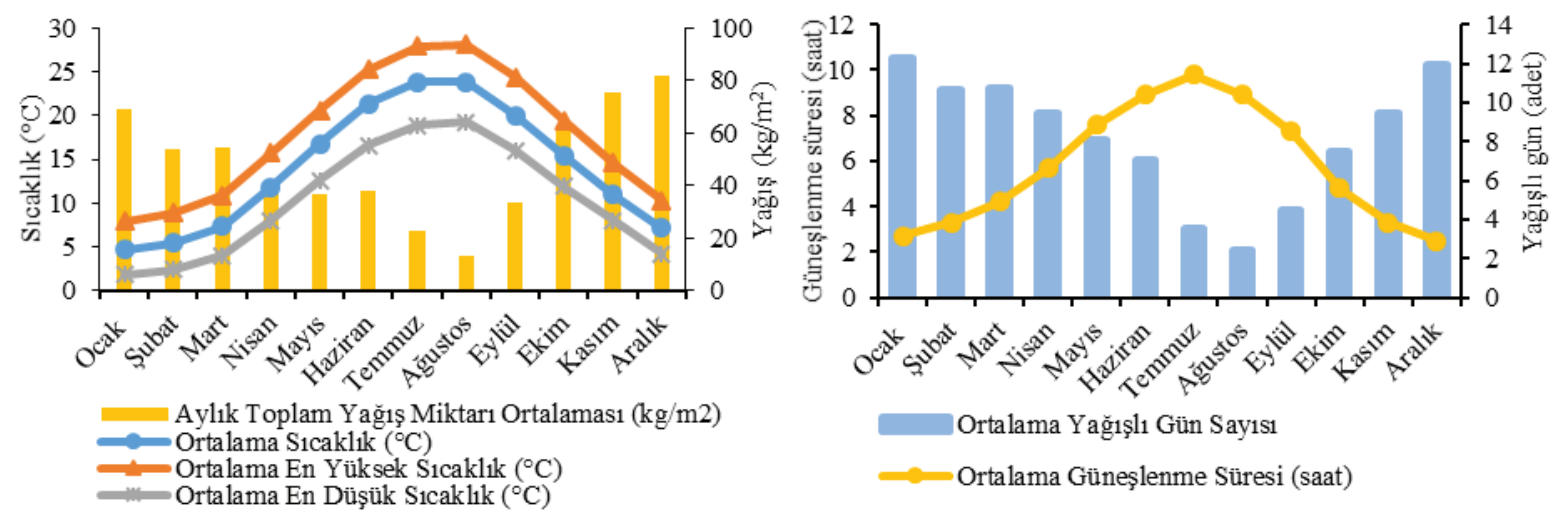

Şekil 1. Tekirdağ uzun yıllar iklim değerleri

Tekirdağ Etkili Sicaklık Toplamı (EST) 1939-2017 y1llar ortalamasına göre 1887,00 günderece ile III. sınıfta iken 2013-2018 yılları arasında; 2017 y1lı 1968,00 gün-derece ile en düşük ve 2016 yılı 2247,73 gün-derece ile en yüksek olarak hesaplanmıştır. Tekirdağ 2013, 2014, 2015 ve 2017 yıllarında IV. sınıfta 2016 ve 2018 yıllarında V. iklim sınıfında yer almıştır. Hidrotermik Gösterge bakımından uzun yıllar ortalaması $3437,63{ }^{\circ} \mathrm{C} . \mathrm{mm}$ 'dir. Son alt1 yılda Hidrotermik Gösterge 1376,32 ${ }^{\circ} \mathrm{C} . \mathrm{mm}$ ile 2013 yılında en düşük ve 10159,04 ${ }^{\circ} \mathrm{C} . \mathrm{mm}$ ile 2014 yılında olağandış1 şekilde yüksek olarak hesaplanmıştır. 2014 yılındaki bu değer il genelinde verim ve kalite açısından olağanüstü zarara neden olmuştur. Tekirdağ'da Branas Heliotermik Göstergesi uzun yıllar ortalaması 6,24 olarak hesaplanmaktadır. 2013-2018 yılları arasında bu değerler 4,69 ile 7,50 arasında değişmiştir. Tüm değerler sınır değer olan 2,6'dan büyük olmakla beraber, dalgalanma özellikle kalite açısından yetiştiricilikte görülen zorlukları ifade etmektedir. Huglin Heliotermik Gösterge değerlerine göre belirli bir bölgede yetişmesi muhtemel çeşitler belirlenebilmektedir (Köse 2014). Tekirdağ ili uzun yıllar ortalaması 2132,82 değeri ile 1lıman iklim sınıfında yer alırken 2013 ve 2015 yılları çok sıcak, 
2014 ve 2017 yılları 1lıman ve 2016 ile 2018 yılları sıcak iklim sınıfinda yer almıştır. Kuraklık Göstergesi Tekirdağ'da 1939-2017 yılları arası 0,43 olarak hesaplanmıştır. Bu anlamda yıllık toplam yağış, vejetasyon periyodundaki yağış ve Hidrotermik Gösterge değerleriyle birlikte incelendiğinde özellikle şaraplık çeşitlerin yetiştiriciliği açısından kuraklı̆̆ın irdelenmesinde tek başına yetersiz kalabilmektedir. Gece Serinlik Göstergesi uzun yıllar ortalamasında $16,00{ }^{\circ} \mathrm{C}$ iken, $2013-2018$ yılları arası $12,60{ }^{\circ} \mathrm{C}$ ve $18,20^{\circ} \mathrm{C}$ arasında değişmiştir. Uzun yıllar ortalamasına göre Tekirdağ'da geceler 1lık olarak değerlendirilmektedir. Kısa dönem iklim verilerine göre ise genelde 1lık ve 2018 yılında sıcak iklim sınıfındadır. Kuruluk Göstergesine göre Tekirdağ uzun yıllar ortalamasında $-131,00 \mathrm{~mm}$ ile çok kuru iklim sınıfında yer almaktadır. 2013-2018 yılları arasında hesaplanan değerler aynı doğrultudadır. Kuraklık Göstergesinde olduğu gibi Kuruluk Göstergesinde de bu değerler toplam yağış, vejetasyon periyodundaki yağış ve Hidrotermik Gösterge değerleriyle birlikte incelendiğinde Kuruluk Göstergesinin bağlardaki su dengesinin incelenmesinde tek başına yetersiz kalabildiğini göstermektedir (Çizelge 6).

Çizelge 6. Tekirdağ iklim göstergelerinin uzun yıllar ve son altı yıllık değişimleri

\begin{tabular}{|c|c|c|c|c|c|c|c|}
\hline Tekirdağ & $1939-2017$ & 2013 & 2014 & 2015 & 2016 & 2017 & 2018 \\
\hline Etkili sıcaklık toplamı (gün-derece) & 1887,00 & 2157,00 & 2074,64 & 2142,00 & 2247,73 & 1968,00 & 2235,00 \\
\hline Hidrotermik gösterge $\left({ }^{\circ} \mathrm{C} . \mathrm{mm}\right)$ : & 3437,63 & 1376,32 & 10159,04 & 3380,96 & 1745,33 & 2867,24 & 4945,65 \\
\hline Heliotermik gösterge ( ${ }^{\circ} \mathrm{C}$.saat) & 6,24 & 7,50 & 4,69 & 6,17 & 7,06 & 5,78 & 5,16 \\
\hline Huglin heliotermik göstergesi & 2132,82 & 3044,70 & 2342,78 & 3007,98 & 2582,02 & 2223,09 & 2438,82 \\
\hline Kuraklık göstergesi & 0,43 & 0,15 & 1,05 & 0,40 & 0,19 & 0,34 & 0,47 \\
\hline Gece serinlik göstergesi $\left({ }^{\circ} \mathrm{C}\right)$ & 16,00 & 13,60 & 16,71 & 12,60 & 17,47 & 17,80 & 18,20 \\
\hline Kuruluk göstergesi (mm) & $-131,00$ & $-206,00$ & $-29,00$ & $-167,00$ & $-194,00$ & $-156,00$ & $-138,00$ \\
\hline
\end{tabular}

Kırklareli için 1959-2017 yılları arasını kapsayan uzun yıllar iklim verilerine göre; yıllık ortalama sicaklık $13,25{ }^{\circ} \mathrm{C}$ 'dir. En soğuk ay $2,9^{\circ} \mathrm{C}$ ile Ocak, en sicak ay $23,9{ }^{\circ} \mathrm{C}$ ile Temmuz ayıdır. Yıllık ortalama yağış miktarı 573,6 mm'dir. En fazla yağışın olduğu dönem Kasım-Ocak arası, vejetasyon periyodunda ortalama yağış miktarı 223,0 mm' dir (MGM 2018b). İl merkezinde en yüksek değerler 2000 yılı Temmuz ayında $42,5{ }^{\circ} \mathrm{C}$, en düşük değer 1972 yılı Ocak ayında $-15,8{ }^{\circ} \mathrm{C}$ olarak ölçülmüştür (MGM 2018b). Yağış miktarı Aralık ayında en fazla $\left(70,6 \mathrm{~kg} / \mathrm{m}^{2}\right)$, Ağustos ayında en azdır $\left(21,1 \mathrm{~kg} / \mathrm{m}^{2}\right)$. En az yağışlı gün görülen ay 3,6 gün ile Ağustos, en fazla yağışlı gün görülen ay 11,4 gün ile Ocak’tır (Şekil 2). Ortalama yağışlı gün sayısı ise 98,1 gündür (MGM 2019b).
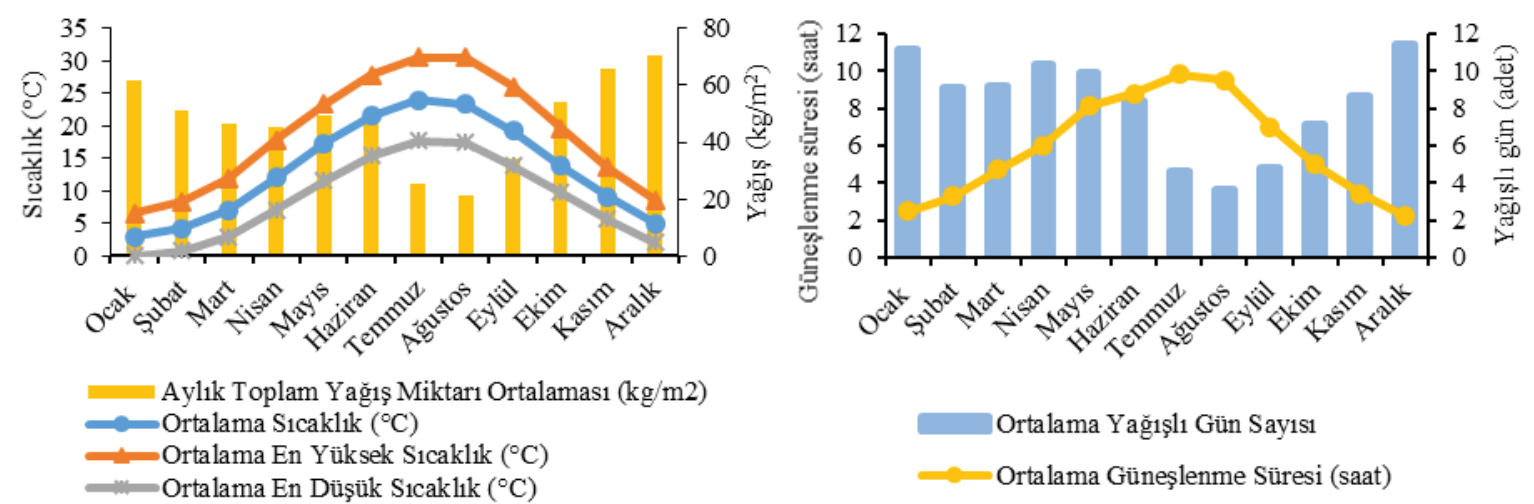

Şekil 2. Kırklareli uzun yıllar iklim değerleri

EST değeri Kırklareli için 1959-2017 yılları arasında 1848,00 gün-derece olarak hesaplanmakta ve uzun yıllar ortalaması bakımından III. iklim sınıfına yer almaktadır. Son dönemde ise yalnızca 2014 y1lı 1914,00 gün-derece ile bu sınıfa girmiştir. Geriye kalan dört yıl IV. iklim sınıfında, 2018 y1lı ise V. iklim sınıfında yer bulmuştur. Hidrotermik Gösterge uzun yıllar ortalaması $4191,22^{\circ} \mathrm{C} . \mathrm{mm}$ 'dir. 2014 ve 2018 yılları $8819,68^{\circ} \mathrm{C} . \mathrm{mm}$ ve $6733,20^{\circ} \mathrm{C} . \mathrm{mm}$ değerleri ile eşik değerin üzerinde, diğer yıllar $3195,42^{\circ} \mathrm{C}$.mm ve $3894,86^{\circ} \mathrm{C} . \mathrm{mm}$ değerleri arasında hesaplanmış ve uzun y1llar ortalamasının altına kalmıştır. Heliotermik Gösterge değerleri kısa dönem iklim verilerine göre 3,98 ${ }^{\circ} \mathrm{C}$.saat ve $5,62{ }^{\circ} \mathrm{C}$.saat arasında değişmiştir. Son altı yılın tamamında değerler 1959-2017 ortalaması olan 5,83 ${ }^{\circ}$ C.saat'in altında kalmıştır. Huglin Heliotermik Göstergesine göre Kırklareli uzun y1llar ortalamasında 2354,67 değeri ile 1lıman iklim sınıfında yer almaktadır. Çalışmanın yürütüldüğü 
yılların tamamı 2481,66 ve 2749,41 değerleri arasında hesaplanmış ve Kırklareli’nin sıcak iklim sınıfına kaydığı görülmüştür. Kuraklık Göstergesi 1959-2017 yılları için 0,56 olarak hesaplanmıştır. 2013-2018 yılları arasında yalnızca 2014 yılında 1,17 değeri görülmüştür. Diğer yıllar ortalamaya paralel seyretmiş, 2017 yılında 0,70 değeri ile hafif bir yükseliş görülmüştür. Gece Serinlik Göstergesi uzun yıllar ortalaması $1959-2017$ arasında $13,90{ }^{\circ} \mathrm{C}$ olarak hesaplanmaktadır. Son yıllarda bu değerin $14,10^{\circ} \mathrm{C}$ ve $16,90{ }^{\circ} \mathrm{C}$ arasında değişmesi ve iklim sınıfının 1lık gecelere kayması dikkat çekmektedir. Kuruluk Göstergesi bakımından uzun yıllar ortalaması $-122,00 \mathrm{~mm}$ 'dir. Son altı yılın tamamında değerler ortalamaya paralel seyretmekte ve Kırklareli çok kuru iklim sınıfında değerlendirilmektedir (Çizelge 7).

Çizelge 7. Kırklareli iklim göstergelerinin uzun yıllar ve son altı yıllık değişimleri

\begin{tabular}{|c|c|c|c|c|c|c|c|}
\hline Kırklareli & $1959-2017$ & 2013 & 2014 & 2015 & 2016 & 2017 & 2018 \\
\hline Etkili sıcaklık toplamı (gün-derece) & 1848,00 & 2034,00 & 1914,00 & 2073,00 & 2121,00 & 2094,00 & 2223,00 \\
\hline Hidrotermik gösterge $\left({ }^{\circ} \mathrm{C} . \mathrm{mm}\right)$ : & 4191,22 & 3705,20 & 8819,68 & 3894,86 & 3195,42 & 3750,10 & 6733,20 \\
\hline Heliotermik gösterge $\left({ }^{\circ} \mathrm{C}\right.$.saat $)$ & 5,83 & 4,92 & 5,62 & 5,58 & 5,46 & 3,98 & 4,10 \\
\hline Huglin heliotermik göstergesi & 2354,67 & 2578,05 & 2481,66 & 2659,14 & 2749,41 & 2680,56 & 2720,34 \\
\hline Kuraklık göstergesi & 0,56 & 0,41 & 1,17 & 0,47 & 0,41 & 0,48 & 0,70 \\
\hline Gece serinlik göstergesi $\left({ }^{\circ} \mathrm{C}\right)$ & 13,90 & 14,10 & 14,80 & 16,90 & 14,70 & 15,60 & 15,80 \\
\hline Kuruluk göstergesi (mm) & $-122,00$ & $-150,00$ & $-28,00$ & $-154,00$ & -170 & -163 & $-108,00$ \\
\hline
\end{tabular}

Çanakkale için 1928-2017 yılları arasını kapsayan uzun yıllar iklim verilerine göre; yıllık ortalama sicaklık $15,02{ }^{\circ} \mathrm{C}$, en soğuk ay $6,1^{\circ} \mathrm{C}$ ile Ocak, en sicak ay $25,0^{\circ} \mathrm{C}$ ile Temmuz ayıdır. Yillık ortalama yağış miktarı 616,3 mm'dir. En fazla yağış Kasım-Ocak arası görülürken, vejetasyon periyodunda ortalama yağış 139,0 mm'dir. En yüksek sıcaklık değeri 2017 yılı Ağustos ayında $41,7^{\circ} \mathrm{C}$ ve en düşük değer $-11,5^{\circ} \mathrm{C}$ olarak 1929 yılı Ocak ayında gerçekleşmiştir. Çanakkale'nin hâkim rüzgâr yönü Kuzey-kuzeydoğudur. En hızlı rüzgar 139,3 km/sa ile 1991 yılı Şubat ayında ölçülmüştür. Çanakkale'de yıllık bağıl nem ortalaması \%72,6'dır. Yağış miktarı Aralık ayında en fazla $\left(106,8 \mathrm{~kg} / \mathrm{m}^{2}\right)$, Ağustos ayında en azdır $\left(6,4 \mathrm{~kg} / \mathrm{m}^{2}\right)$. Yağışlı günler yıl içinde en az 1,3 gün ile Ağustos ayında, en fazla 12,6 gün ile Aralık ayında görülmektedir (Şekil 3). Ortalama yağışlı gün sayısı ise 84,8 gündür (MGM 2019c).
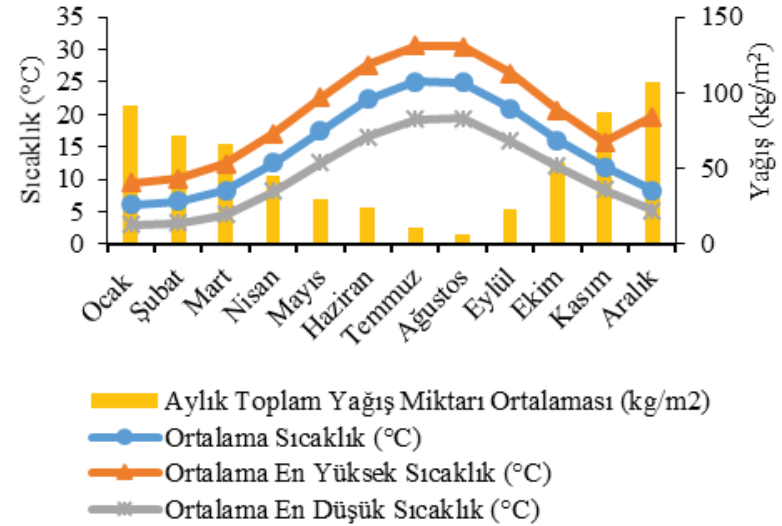

Şekil 3. Çanakkale uzun yıllar iklim değerleri

Çanakkale iklim göstergelerinin uzun yıllar ortalamaları ve yıllık değişimleri Çizelge 8'de görülmektedir. EST değeri 1928-2017 yılları arasında 2073,00 gün-derece olarak hesaplanmıştır ve IV. iklim sınıfında yer almıştır. Çalışmanın yapıldığı $2013-2018$ arasında yalnızca 2015 yılı 2178,00 gün-derece ile aynı sınıfta yer almış, diğer beş yıl ise 2205,00 gün-derece'nin üzerinde hesaplanmıştır. Söz konusu yıllarda Çanakkale ili EST değerleri V. iklim sınıfında yer almıştır. Hidrotermik Gösterge değerleri uzun yıllar ortalaması $2532,12^{\circ} \mathrm{C} . \mathrm{mm}$ 'dir. Son alt1 y1lda hesaplanan Hidrotermik Gösterge değerleri dalgalı seyir izlemektedir. 2014, 2015 ve 2018 yılları uzun yıllar ortalamasının üzerinde, 2013, 2016 ve 2017 yılları altındadır. Bu durum yağış rejiminin son yıllardaki istikrarsızlığı ve özellikle vejetasyon döneminde alınan istenmeyen yağışları göstermektedir. Heliotermik Gösterge değerleri 2013, 2014, 2015 ve 2016 yıllarında 1928-2017 ortalamasına yakın seyrederken 2017 ve 2018 'de uzun yıllar ortalamasının altında değerler dikkat çekicidir. Bununla birlikte bu düşük değerler 
2,6 ${ }^{\circ}$ C.saat olan eşik değerin üzerindedir. Huglin Heliotermik Göstergesi 1928-2017 ortalamas1 2414,34 olarak hesaplanmıştır. Bu değer ile Çanakkale'nin sıcak iklim sınıfında olduğu görülmektedir. Son dönemde bu değerler 2492,00 ve 2769,30 arasında değişmiştir. Huglin Heliotermik Göstergesine göre Çanakkale iklim sınıfında değişiklik görülmemektedir. Kuraklık Göstergesine göre Çanakkale uzun yıllar ortalaması 0,31 olarak hesaplanmıştır. Son dönemde 2014 ve 2016 yıllarında artış görülmekle birlikte diğer dört yıl için ortalamaya yakın değerler hesaplanmıştır. Gece Serinlik Göstergesi uzun yıllar değerleri 1lık geceleri işaret etmektedir. 2013-2018 yılları arasında 2015 ve 2018 yıllarında gece sıcaklıkları yükselmiştir. Diğer dört yılda Gece Serinlik Göstergesi sürekli olarak uzun yıllar ortalamasından yüksektir. Çanakkale Kuruluk Göstergesi değerleri gerek 1928-2017 ortalamasında gerekse 2013-2018 yılları arasında istikrarlı olarak çok kuru iklim sınıfında yer almaktadır (Çizelge 8).

Çizelge 8. Çanakkale iklim göstergelerinin uzun yıllar ve son altı yıllık değișimleri

\begin{tabular}{lccccccc}
\hline Canakkale & $1928-2017$ & 2013 & 2014 & 2015 & 2016 & 2017 & 2018 \\
\hline Etkili sıcaklık toplamı (gün-derece) & 2073,00 & 2292,00 & 2220,00 & 2178,00 & 2472,00 & 2313,00 & 2445,00 \\
Hidrotermik gösterge ( $\left({ }^{\circ} \mathrm{C} . \mathrm{mm}\right):$ & 2532,12 & 2115,80 & 6087,38 & 4184,46 & 1751,98 & 1992,16 & 4733,15 \\
Heliotermik gösterge $\left({ }^{\circ} \mathrm{C} . s a a t\right)$ & 8,13 & 9,62 & 7,71 & 7,58 & 9,37 & 4,72 & 5,66 \\
Huglin heliotermik göstergesi & 2414,34 & 2646,90 & 2492,37 & 2584,17 & 2769,30 & 2714,22 & 2729,52 \\
Kuraklık göstergesi & 0,31 & 0,25 & 0,59 & 0,53 & 0,16 & 0,17 & 0,38 \\
Gece serinlik göstergesi $\left({ }^{\circ} \mathrm{C}\right)$ & 15,90 & 16,60 & 17,20 & 19,90 & 17,90 & 17,40 & 18,00 \\
Kuruluk göstergesi (mm) & $-165,00$ & $-199,00$ & $-122,00$ & $-153,00$ & $-209,00$ & $-201,00$ & $-160,00$ \\
\hline
\end{tabular}

Edirne'de 1930-2017 yılları arasını kapsayan uzun yıllar verilerine göre; y1llık ortalama sicaklık $13,76{ }^{\circ} \mathrm{C}$, en soğuk ay $-0,6{ }^{\circ} \mathrm{C}$ ile Ocak, en sicak aylar $31,7{ }^{\circ} \mathrm{C}$ ile Temmuz ve Ağustos aylarıdır. Yıllık ortalama yağış 604,88 mm'dir. En fazla yağış Kasım-Ocak arasında olup, vejetasyon periyodunda ortalama yağış 238,7 mm'dir. Edirne'de en yüksek sıcaklık değeri 2007 yılı Temmuz ayında $44,1^{\circ} \mathrm{C}$, en düşük değer 1954 yılı Ocak ayında $-19,5{ }^{\circ} \mathrm{C}$ olarak ölçülmüştür. Hakim rüzgar Kuzey rüzgarıdır. En hızlı rüzgar 104,0 km/sa ile 1970 yılı Şubat ayında görülmüştür. Uzun yıllar ortalamalarına göre yağış miktarı Aralık ayında en fazla $\left(70,0 \mathrm{~kg} / \mathrm{m}^{2}\right)$, Ağustos ayında en azdır $(22,4$ $\mathrm{kg} / \mathrm{m}^{2}$ ). Yağışlı günler 3,9 gün ile en az Ağustos ayında, en fazla 13,2 gün ile Aralık ayında görülmektedir (Şekil 4). Ortalama yağışlı gün sayısı ise 106,7’dir (MGM 2019d).
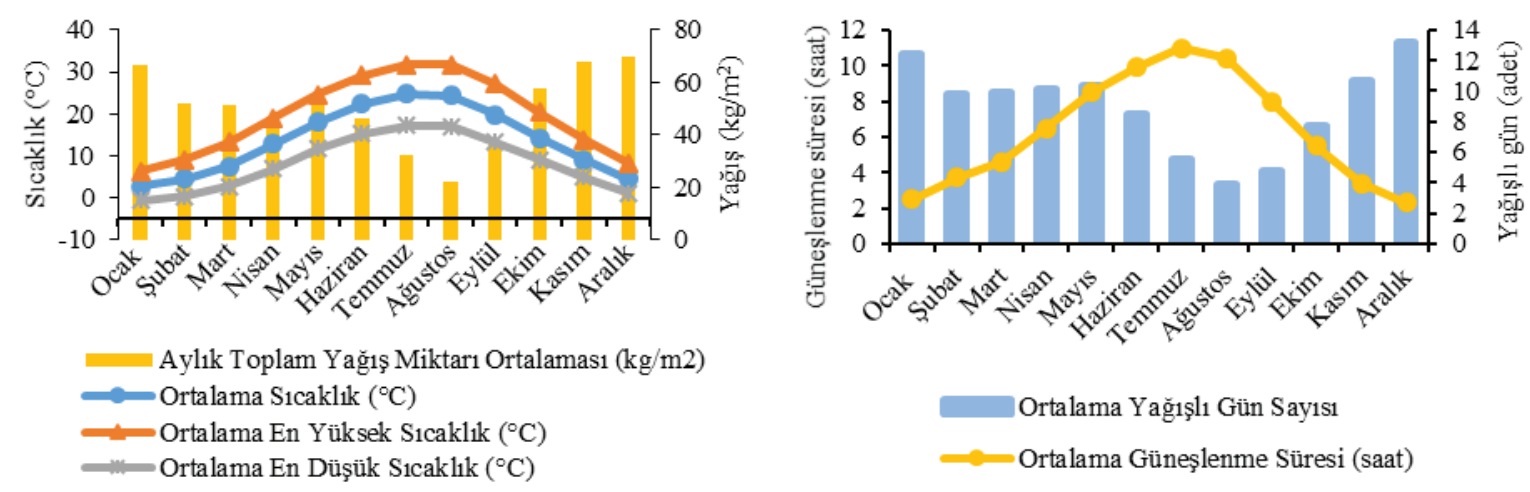

Şekil 4. Edirne uzun yıllar iklim değerleri

EST değerleri bakımından Edirne son altı yılın dördünde 1930-2017 ortalaması olan 2001,00 gün-derece'nin üzerinde hesaplanmış ve V. iklim sınıfında yer almıştır. Bu durum bölgenin diğer illerinde de olduğu gibi son yıllarda sıcaklık ortalamalarının artış eğiliminde olduğunu göstermektedir. Hidrotermik Gösterge son yıllarda 2013 yılı dişında uzun yıllar ortalaması olan 4700,51 ${ }^{\circ} \mathrm{C} . \mathrm{mm}$ 'nin üzerindedir. Artan sicaklıklarla birlikte vejetasyon döneminde alınan yağışın da yükseldiği görülmektedir. Heliotermik Gösterge 1930-2017 ortalamasında 6,68 olarak hesaplanmıştır. Çalışmanın yürütüldüğü yıllardan yalnızca 2014 yılı 4,59 değeri ile uzun yıllar ortalamasının altında kalırken diğer y1llarda Heliotermik Göstergenin ortalamanın üzerinde olduğu görülmektedir. Huglin Heliotermik Göstergesi uzun yıllar ortalaması 2538,27 olarak hesaplanmıştır. İklim sınıfı olarak Edirne halen sıcak iklimde değerlendirilmekle birlikte, Heliotermik Gösterge son y1llarda ortalamanın üzerinde ve 3000,00 değerine yaklaşmaktadır. Bu eğilimin sürmesi durumunda Edirne'nin çok sicak iklim sınıfına kayacağı öngörülebilmektedir. Kuraklık Göstergesi bakımından 2014 dışında 1 sınır değerine yaklaşan 
y1l görülmemektedir. 2015 ve 2017 y1llarında yağışın ortalamaların üzerinde olduğu görülmüştür. Gece Serinlik Göstergesi değerleri 1930-2017 yılları arasında Edirne'nin serin geceler iklim sınıfına dahil olduğunu göstermekte, son y1llarda 1lık gecelerin sıklaştığ 1 söylenebilmektedir. Bu durum yetiştiricilik açısından renklenme ve kalite sorunlarının artabileceği şeklinde yorumlanabilir. Kuruluk Göstergesi değerleri 2014 yılında -52,00 olarak hesaplanmış ve Edirne orta kuru iklim sınıfında yer almıştır. Uzun yıllar ortalamaları ve diğer 5 yıl ise çok kuru iklim sınıfında yer almıştır (Çizelge 9).

Çizelge 9. Edirne iklim göstergelerinin uzun yıllar ve son altı y1llık değişimleri

\begin{tabular}{|c|c|c|c|c|c|c|c|}
\hline Edirne & $1930-2017$ & 2013 & 2014 & 2015 & 2016 & 2017 & 2018 \\
\hline Etkili sıcaklık toplamı (gün-derece) & 2001,00 & 2325,00 & 2085,00 & 2037,00 & 2358,00 & 2244,00 & 2424,00 \\
\hline Hidrotermik gösterge $\left({ }^{\circ} \mathrm{C} . \mathrm{mm}\right)$ : & 4700,51 & 3742,17 & 9178,96 & 5513,38 & 4095,33 & 6398,02 & 5043,62 \\
\hline Heliotermik gösterge ( ${ }^{\circ} \mathrm{C}$.saat) & 6,68 & 8,92 & 4,59 & 7,49 & 9,02 & 8,38 & 7,90 \\
\hline Huglin heliotermik göstergesi & 2538,27 & 2929,95 & 2608,65 & 2761,65 & 2951,37 & 2888,64 & 2966,67 \\
\hline Kuraklık göstergesi & 0,58 & 0,36 & 0,98 & 0,68 & 0,44 & 0,64 & 0,47 \\
\hline Gece serinlik göstergesi $\left({ }^{\circ} \mathrm{C}\right)$ & 13,30 & 13,90 & 14,50 & 16,30 & 14,40 & 15,40 & 15,30 \\
\hline Kuruluk göstergesi (mm) & $-124,00$ & $-171,00$ & $-52,00$ & $-114,00$ & $-181,00$ & $-133,00$ & $-154,00$ \\
\hline
\end{tabular}

\section{Sonuç}

Trakya Bölgesini temsilen incelenen illerin tamamında EST değerlerinin dolayısıyla sıcaklıkların artış halinde olduğu net bir şekilde görülmektedir. Hidrotermik Gösterge, Kuraklık Göstergesi ve Kuruluk Göstergesi değerlerine göre özellikle vejetasyon dönemindeki yağış rejiminin istikrarsızlaşma eğiliminde olduğu ve olağandışı iklim olaylarında sayı ve sıklığın artacağı düşünülmektedir. Bununla birlikte özellikle şaraplık çeşitlerin yetiştiriciliği açısından Kuraklık Göstergesi ve Kuruluk Göstergesinin bölge ve ülke şartlarında yanıltıcı olacağı söylenebilir. Bu göstergelerin küresel ölçekteki bağcılık alanlarını ifade ettiği unutulmamalıdır. Hidrotermik Göstergenin bölge şartlarında yağış rejimi ve buna bağlı olarak karşılaşılabilecek sorunları öngörmekte daha kullanışlı olduğu söylenebilmektedir. Huglin Heliotermik Göstergesine göre bölgenin tamamında sıcaklıklar ortalamalara göre artış eğilimindedir. Gece Serinlik Göstergesi daha çok renklenme ve kalite ile ilişkilendirilen bir göstergedir. Ortalama sıcaklıkların artışı yavaş da olsa gece sıcaklarında artışa neden olmakta, kalite olumsuz etkilenmektedir.

Tüm göstergelerin işaret ettiği nokta; sıcaklıkların artışı ve yağışın miktarında henüz çok değişiklik olmamakla birlikte özelikle alınan yağışın döneminin değişmesidir. Olağandışı iklim olayları artmaktadır. İklim değişikliği etkileri öngörülen olmanın ötesinde yaşanır hale gelmiştir.

$\mathrm{Bu}$ nedenle bölgede bulunan iklim istasyonlarının sayısı arttırılarak ya da özellikle eğitim ve bilinç seviyesi daha yüksek üreticilerin bağlarında bulunan istasyonlardan da veriler alınarak hem noktasal hem bölgesel ölçekte daha detaylı analizler yapılmalıdır. Bu sayede bölge içindeki mikroklima alanlarına geleceğe yönelik çeşit önerileri ve kültürel işlem yönetiminin daha sağlıklı olması sağlanabilir.

Bağcılıkta her vejetasyon döneminin mevsimsel etkileri asıl belirleyici faktördür. Dolayısıyla, her yıl yapılacak kültürel uygulamaların planlaması uzun ve orta vadeli meteorolojik değerlendirmeler takip edilerek ayrı ayrı yapılmalı, kısa vadeli meteorolojik riskler değerlendirilerek fenolojik döneme göre müdahaleler düşünülmelidir.

Yeni iklim koşullarına uygun yeni çeşit ve anaçların 1slahı yanında, mevcut genetik kaynakların daha verimli kullanılması ve ekonomik anlamda üretime kazandırılması önemlidir. İklim değişikliği etkilerinden korunmak ve uyum sağlayarak geçiş sürecini en az zararla atlatmak için, kısa dönemde toprak yönetimi (sulama programlarını düzenlenmesi, örtü bitkileri kullanımı, yaprak su potansiyelinin takibi ve gübre kontrolü), asma tacı yönetimi (sürgün yönlerinin ayarlanması, asmalara uygun terbiye şekli verilmesi, minimum budama, mikroklima yönetimi, yaprakları aşırı güneşten koruyan spreyler vb.) gibi yetiştiricilik tekniği ile ilgili uygulamalar dikkate alınmalıdır. Uzun dönemde ise çeşitlerin ve bağc1lık bölgelerinin değiştirilmesi gibi stratejiler denenmelidir.

\section{Kaynaklar}

Bahar, E., Korkutal, İ., Boz Y., 2010 Tekirdağ ili Şarkoy ilcesi’ nin terroir açısından değerlendirmesi. Tekirdağ İli Değerleri Sempozyumu. 156-177.

Branas, J., Bernon, G., Levadoux, L., 1946. Élements de Viticultura Générale. Imp. Déhan, Bordeaux.

Branas, J., 1974. Viticulture. Imp, Dehan, Montpellier. 
Carbonneau, A., Deloire, A., Jaillard, B., 2007. La Vigne. Physiologie, Terroir, Culture. Dunod, Paris, ISBN: 9782100499984.

Donat, M.G., Alexander, L.V., Yang, H., Durre, I., Vose, R., Caesar, J., 2013. Global land-lased datasets for monitoring climatic extremes. Bulletin of the American Meteorological Society 94: 997-1006.

EPA (United States Environmental Protection Agency) 2013. Weather and climate. http://www.epa.gov/climatechange/science/indicators/weather-climate/ ( 12/01/2013)

FAO (Food and Agriculture Organization of the United Nations) 2013. Climate-smart agriculture sourcebook. http://www.fao.org/docrep/018/i3325e/i3325e.pdf (07/02/2019).

Gönençgil, B., 2012. Climate characteristics of thrace and observed temperature - precipitation trends. The $2^{\text {nd }}$ International Balkan Conference: Conference Proceeding Book. Vol.2 SY 80-95

Huglin, P., 1978. Nouveau Mode D’évaluation Des Possibilités Héliothermiques D’un Milieu Viticole. in: Proc. Symp. Int. Sur L'ecologie De La Vigne. Ministère De l'Agriculture Et De l'Industrie Alimentaire, Contança. Pp. 89- 98.

Immerfall, S., 2009.Handbook of European Societies: Social Transformations in the $21^{\text {st }}$ Century. Springer. p.417.ISBN978-0-387-88198-0.

Jones, G.V., 2006. Climate and terroir: impacts of climate variability and change on wine. in: fine wine and terroir. The Geoscience Perspective. Pp. 203-216. Geoscience Canada Reprint Series Number 9, Geological Association Of Canada, St. John's, Newfoundland, 247 Pages.

Köse, B., 2014. Phenology and ripening of Vitis vinifera L. and Vitis labrusca L. varieties in the maritime climate of Samsun in Turkey's Black Sea Region S. Afr. J. Enol. Vitic., Vol. 35, No. 1, 2014

Kunter, B., Cantürk, S., Keskin, N., Çetiner, H., 2017. Etkili sıcaklık toplamı ile fenoloji arasındaki ilişkiden yararlanarak Ankara ili bağcılık potansiyelinin belirlenmesi. 5. Uluslararası Katılımlı Toprak ve Su Kaynakları Kongresi, 1, 545-552.

Laget, F., Tondut, JL., Deloire, A., Kelly, MT., 2008. Climate trends in a specific mediterranean viticultural area between 1950 and 2006. J. Int. Sci. Vigne Vin., 42(3): 113-123.

Malheiro, AC., Santos, JA., Fraga, H., Pinto, JG., 2010. Climate change scenarios applied to viticultural zoning in europe. Climate Res. 43(3), 163.

Meteoroloji Genel Müdürlüğü (MGM) (2019a). Tekirdağ ili genel istatistik verileri. https://www.mgm.gov.tr/veridegerlendirme/il-ve-ilceler-istatistik.aspx?m=TEKIRDAG (Son erişim tarihi 07.02.2019)

Meteoroloji Genel Müdürlüğü (MGM) (2019b) Kirklareli ili genel istatistik verileri. https://www.mgm.gov.tr/veridegerlendirme/il-ve-ilceler-istatistik.aspx?k=A\&m=KIRKLARELI (Son erişim tarihi 07.02.2019)

Meteoroloji Genel Müdürlüğü (MGM) (2019c). Çanakkale ili genel istatistik verileri. https://www.mgm.gov.tr/veridegerlendirme/il-ve-ilceleristatistik.aspx?k=undefined\&m=CANAKKALE (Son erişim tarihi 07.02.2019)

Meteoroloji Genel Müdürlüğü (MGM) (2019d). Edirne ili genel istatistik verileri. https://www.mgm.gov.tr/veridegerlendirme/il-ve-ilceler-istatistik.aspx?k=A\&m=EDIRNE（Son erişim tarihi 07.02.2019)

Özelkan, E., Bağ1ş, S., Özelkan, EC., Üstündağ, BB., Örmeci, C., 2014. Land surface temperature retrieval for climate analysis and association with climate data. European Journal of Remote Sensing - 2014, 47: 655-669 doi: 10.5721/EuJRS20144737

Papp, B., Sabovijevic, M., 2003. Contribution to the bryophyte flora of Turkish Thrace. Studia Bot. Hung. 34, pp. 43-54, 2003

Riou, C., Pieri, P., Leclech, B., 1994. Consommation d'eau de la vigne en conditions hydriques non limitantes. formulation simplifiée de la transpiration. Vitis, 33, 109-115.

Sensoy, S., Tastekin, A.T., 2005. Temperature assessment of 2005 spring season. http://www.mgm.gov.tr/files/kurumsal/ekitap/4mevsim1/4mevsim1-sayfa27.pdf (Son erişim tarihi 09/08/2016).

Tonietto, J., 1999. Les Macroclimats Viticoles Mondiaux Et Le`Influence Du Mesoclimat Sur La Typicite De La Syrah Et Du Muscat De Hambourg Dans Le Sud De La France: Metodologie De Caracterisation. These Doctorant. Ecole Nationale Superieure Agronomique, Montpellier, 233pp.

Tonietto, J., Carbonneau, A., 2004. A multicriteria climatic classification system for grape growing regions worldwide. Agricultural and Forest Meteorology 124: 81-97.

Winkler, A., Cook, W., Kliewer, L., 1974. General Viticulture. University of California Press, Berkeley.710 Pages.

Zdanowski, J., 2014. Middle Eastern Societies in the $20^{\text {th }}$ Century. Cambridge Scholars Publishing. p.11.ISBN978-1443869591. 